\title{
Five-year follow-up of treatment outcomes in patients with early-stage breast cancer and clinically negative axillary nodes treated with no lymph node dissection or axillary clearance
}

\author{
This article was published in the following Dove Press journal: \\ Breast Cancer:Targets and Therapy \\ 24 August 2012 \\ Number of times this article has been viewed
}

\section{Daigo Yamamoto' \\ Kanji Tanaka² \\ Yu Tsubota' \\ Noriko Sueoka' \\ Tetsuji Shoji ${ }^{3}$ \\ Kayoko Kuwana' \\ A-Hon Kwon' \\ 'Department of Surgery, \\ Kansai Medical University, Hirakata, \\ ${ }^{2}$ Ribon-Rose Tanaka Kanji Breast \\ Clinic, ${ }^{3}$ Shoji Clinic, Osaka, Japan}

\begin{abstract}
Background: Sentinel lymph node biopsy has steadily replaced axillary lymph node dissection (ALND) for staging clinically node-negative breast cancer. However, ALND remains standard management of the axilla when a tumor-positive sentinel lymph node is identified.

Methods: We identified 460 patients with breast cancer (clinically T1/T2N0M0) from the database for 1999-2004. Patient age ranged from 26 to 81 (median 50) years. Patients who underwent mastectomy or breast-conserving surgery with or without ALND were compared for regional recurrence, disease-free survival, and overall survival.

Results: Patients with ALND $(n=308)$ were compared with the no ALND group $(n=152)$. Five-year overall survival and disease-free survival were not significantly different between the two groups, while there was a significant difference between them for regional recurrence. Of the 152 patients who did not undergo axillary dissection, four developed ipsilateral axillary disease, most of whom were rescued by delayed axillary dissection. Further, the criterion for identifying lymphedema was used, ie, a $2 \mathrm{~cm}$ circumferential change at any measured location. As a result, the incidence of lymphedema in the ALND group was $12.7 \%$, while it was not seen in the non ALND group.
\end{abstract}

Conclusion: There is a possibility that ALND may be omitted for cT1/T2N0M0 breast cancer through a combination of hormone therapy and adjuvant chemotherapy.

Keywords: breast cancer, axillary lymph node dissection

\section{Introduction}

In breast cancer, axillary lymph node dissection (ALND) had been the gold standard in axillary staging, providing valuable information for the planning of adjuvant therapy and excellent regional disease control. On the other hand, ALND is associated with significant arm morbidity, chronic lymphedema being the most well-known form. Lymphedema of the arm $(2 \%-28 \%)$ and shoulder function impairment $(5 \%-19 \%)$ are the most debilitating, but even more patients suffer from dysesthesia and pain $(23 \%-31 \%){ }^{1-4}$

The National Surgical Adjuvant Bowel and Breast Project (NSABP) B-04 was planned to evaluate the utility of extensive breast surgery 40 years ago. ${ }^{5}$ On the basis of the results of 25 years of follow-up, total mastectomy followed by immediate ALND did not affect overall survival for clinically node-negative and node-positive breast cancer patients in comparison with delayed ALND in cases of regional lymph node recurrence. ${ }^{6}$ However, the initial recurrence rate of regional lymph nodes was
Correspondence: Daigo Yamamoto Department of Surgery,

Kansai Medical University,

Hirakata, Osaka 570-8507, Japan

Tel +8I7 28040 l0 I

Fax +817 28040170

Email yamamotd@hirakata.ac.jp 
unexpectedly low (18\%) for patients with clinically nodenegative breast cancer treated with total mastectomy alone, in whom the incidence of nodal metastases had been estimated to be $30 \%$ based on the pathology results of patients who had been randomized to receive radical mastectomy. Although the reason for this discrepancy is not clear, there is a possibility that axillary surgery may be safely omitted without affecting breast cancer mortality or overall survival.

Recently, sentinel lymph node biopsy has been steadily replacing ALND for staging of clinically node-negative breast cancer. Low locoregional recurrence was observed after a long follow-up in both the NSABP B32 and American College of Surgeons Oncology Group (ASOCOG) Z0011 trials, as well as in NSABP B04. ${ }^{7-10}$ Further, long-term arm morbidity is significantly less common and less severe after sentinel lymph node dissection than after ALND. ${ }^{11}$ However, at present, ALND remains standard management of the axilla when a tumor-positive sentinel lymph node is identified. The aim of this study was to compare ALND and non ALND groups with regard to regional recurrence, disease-free survival, and overall survival in patients with breast cancer.

\section{Materials and methods}

\section{Patients and treatment}

Between July 1999 and April 2004, consecutive patients presenting at Kansai Medical University Hospital with primary breast cancer were recruited, and data collection took place at Kansai Medical University Hospital. All patients provided their written informed consent before entering into this study, which concerns the 460 patients with operable invasive breast cancer and no palpable axillary nodes (clinically T1/T2N0M0) who underwent mastectomy or breast-conserving surgery with $(\mathrm{n}=308)$ or without $(\mathrm{n}=152)$ axillary dissection. Criteria for negative axillary lymph node metastasis are: minor axis of the axillary lymph node under $5 \mathrm{~mm}$ on computed tomography images, and fat tissue in the hilum of the axillary lymph node which does not disappear on ultrasound images. When hormone receptor expression was positive, the patient received endocrine therapy for 5 years. Adjuvant anthracycline-based chemotherapies were administered. Four cycles of AC (doxorubicin $60 \mathrm{mg} / \mathrm{m}^{2}$ and cyclophosphamide $500 \mathrm{mg} / \mathrm{m}^{2}$ ) were administered intravenously on day 1 every 21 days. After breast-conserving surgery, patients with/without ALND received tangential irradiation of the breast region, but irradiation of the axilla or internal mammary chain was not performed. Patients who had breast-conserving surgery underwent irradiation of the breast with two tangential fields on a linear accelerator.
The total dose administered to the entire breast was $50 \mathrm{~Gy}$ in 2-Gy fractions.

Either ALND or no ALND was selected by the patient under informed consent prior to all studies (Figure 1). The groups were then compared for incidence of regional recurrence, disease-free survival, and overall survival. Patients with sentinel lymph node-positive/negative cancer, synchronous bilateral breast carcinoma, and distant metastasis at diagnosis were excluded.

\section{Follow-up}

Patients were followed at our outpatient department, with checks scheduled every 4 months in the first 3 years, every 6 months in the subsequent 2 years, and annually thereafter. Mammography and chest $\mathrm{x}$-ray were performed yearly. At every visit, the patient was checked for locoregional recurrence, signals for distant metastases, and side effects. After 10 years of disease-free follow-up, the patients were discharged. Circumference measures at the metacarpals, wrist, and every $4 \mathrm{~cm}$ along the arm until the axillary fold were taken with the woman seated and the arm resting on a bench in 90 degrees abduction. When change of arm circumference for the treated side was more than $2 \mathrm{~cm}$ that of the circumference on the untreated side, the size difference was considered indicative of lymphedema.

\section{Statistical analysis}

Clinicopathological data were stored. The endpoints of regional recurrence, disease-free survival, and overall survival were used to compare the ALND and non ALND groups. They were analyzed using Kaplan-Meier estimates, and the log-rank test was used to compare the curves. Differences between the two treatment groups were determined using the Chi-squared test. Differences with a $P<0.05$ were considered to be statistically significant. All deaths, irrespective of cause, were taken as an endpoint in overall survival. Patients without an endpoint were censored at the end of their follow-up in the survival analysis.

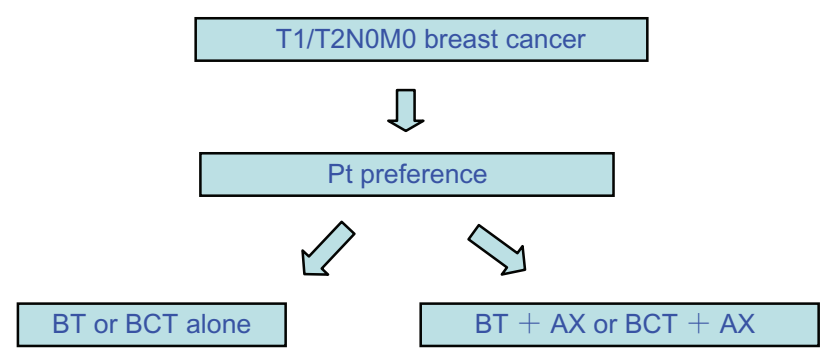

Figure I Schema of the study. 


\section{Results}

Patients with ALND $(n=308)$ were compared with those with no ALND $(n=152)$. Their characteristics are shown in Tables 1 and 2. The age distribution was similar in the two groups. There were no significant differences in histology, presence of lymphovascular invasion, nuclear grade, and presence of adjuvant chemotherapy between the two groups. However, most patients had pT1 disease, with a greater frequency in the no ALND group $(P=0.0047)$. Further, there were significant differences in estrogen, progesterone, and Her-2 receptor status between the two groups. The median follow-up was 60 (16-133) months in the group without axillary dissection, and 79 (14-149) months in the group with axillary dissection.

Twenty-three percent of the 308 patients who received axillary dissection had metastatic axillary lymph nodes. Of the 152 patients who did not receive axillary dissection, four developed ipsilateral axillary disease: most were rescued by delayed axillary dissection. One of these four patients subsequently developed distant relapse and died of breast disease. The median time from primary surgery to axillary occurrence was 49 months in the ALND group and 29.5 months in the no ALND group (Figure 4, Table 3).

There was no significant difference between the two groups with regard to disease-free survival (Figure 2, $P>0.05)$. Similarly, there was no significant difference between the two groups for overall survival. The 5-year overall survival was $95.9 \%$ in the ALND group and $94.0 \%$ in the no ALND group (Figure 3, $P>0.05$ ). The criterion used for identifying lymphedema was a $2 \mathrm{~cm}$ circumferential change at any measured location. The incidence of lymphedema in

Table I Clinicopathological features of breast cancer patients

\begin{tabular}{llll}
\hline & $\begin{array}{l}\text { ALND } \\
(\mathbf{N}=\mathbf{3 0 8})\end{array}$ & $\begin{array}{l}\text { No ALND } \\
(\mathbf{N}=\mathbf{1 5 0})\end{array}$ & P value \\
\hline $\begin{array}{l}\text { Median age (yrs) } \\
\text { Path T - stage }\end{array}$ & 50.3 & 48.8 & \\
$\quad$ Tis & 0 & $2(1.3)$ & 0.047 \\
TI & $162(52.6)$ & $99(66)$ & \\
T2 & $146(47.4)$ & $49(34)$ & \\
Histology & & & \\
IDC & $210(68.1)$ & $131(87.3)$ & 0.97 \\
ILC & $30(9.7)$ & $12(8.0)$ & \\
Other & $68(22.0)$ & $7(4.6)$ & \\
Lymphovascular invasion & & & \\
$\quad$ Yes & $21(6.8)$ & $4(2.6)$ & 0.21 \\
$\quad$ No & $287(93.1)$ & $146(97.3)$ & \\
Nuclear grade & & & \\
I & $574(18.5)$ & $28(18.7)$ & 2.4 \\
II & $132(42.9)$ & $76(50.7)$ & \\
III & $84(27.2)$ & $56(37.3)$ & \\
\hline
\end{tabular}

Table 2 Clinicopathological features of breast cancer patients

\begin{tabular}{|c|c|c|c|}
\hline & $\begin{array}{l}\text { ALND } \\
(N=308)\end{array}$ & $\begin{array}{l}\text { No ALND } \\
(N=150)\end{array}$ & $P$ value \\
\hline \multicolumn{4}{|l|}{ ER and/or PgR } \\
\hline Positive & $248(80.5)$ & $108(72.0)$ & 0.047 \\
\hline Negative & $60(19.5)$ & $42(28.0)$ & \\
\hline \multicolumn{4}{|l|}{$\mathrm{HER} 2 / \mathrm{Neu}$} \\
\hline Yes & $48(15.6)$ & $39(26.0)$ & 0.001 \\
\hline No & $260(84.4)$ & II I (74.0) & \\
\hline \multicolumn{4}{|l|}{ Adjuvant chemo } \\
\hline Yes & 7I (23.0) & $29(19.3)$ & 0.47 \\
\hline No & $189(6 \mid .4)$ & III (74.0) & \\
\hline Unknown & $48(15.6)$ & $10(6.7)$ & \\
\hline Median FU (mos) & $79(14-149)$ & $59(5-127)$ & \\
\hline
\end{tabular}

the ALND group was $12.7 \%$, while it was not seen in the non ALND group (Table $3, P<0.01$ ).

\section{Discussion}

The main issue in this study is regional control and mortality in patients with T1/T2N0M0 breast cancer treated with mastectomy or breast-conserving surgery alone compared with mastectomy or breast-conserving surgery plus ALND. In the present study, there was no difference in overall survival between the ALND and no ALND groups, although among the 308 patients who received axillary dissection, $23 \%$ had metastatic axillary lymph nodes on pathologic examination. We expected that a similar percentage in the no axillary dissection arm would develop axillary metastases during follow-up. However, only 4/152 (2.6\%) patients developed overt axillary disease. These findings suggest that not all metastases in the axilla become biologically active. This finding is consistent with other studies ${ }^{1,2}$ reporting that the axillary recurrence rate is much lower than the rate of axillary involvement on pathologic examination of resected axillary nodes. The reason why the involved nodes disappeared is unclear, but one possibility is that the postsurgical adjuvant therapies were effective at controlling local tumor growth. In fact, in this study, doxorubicin and cyclophosphamide were administered as adjuvant therapy four times, and/or tamoxifen was prescribed for 5 years.

Table 3 Recurrence and lymphedema

\begin{tabular}{lll}
\hline & ALND (N = 308) & No ALND (N = I 50) \\
\hline $\begin{array}{l}\text { Local and regional } \\
\text { recurrence }\end{array}$ & $\mathrm{I}$ & $4^{*}$ \\
Lymphedema & 39 & 0 \\
$\begin{array}{l}\text { Median time to } \\
\text { recurrence (mos) }\end{array}$ & 49 & $29.5(19-40)$ \\
\hline Note: *Delayed ALND was done in three cases of regional lymph node recurrence.
\end{tabular}




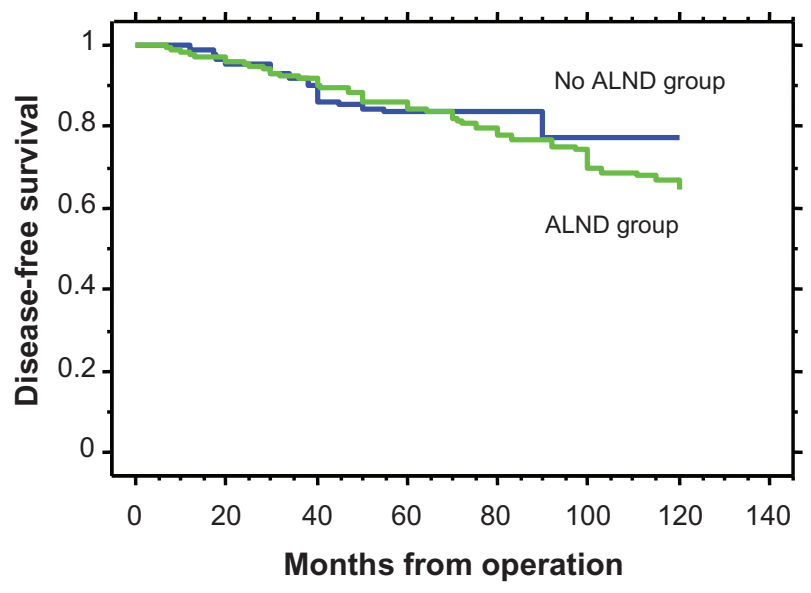

Figure 2 Disease-free survival curves.

Note: The green line shows the ALND group, and the blue line shows the no ALND group (log-rank $P>0.05$ ).

Abbreviation: ALND, axillary lymph node dissection.

Therefore, the adjuvant therapy is effective and, thus, no ALND may be a safe alternative. However, it is hard to draw firm conclusions in this nonrandomized setting. ALND may be associated with more accurate staging and improved regional control, but it does not affect breast cancer mortality or overall survival.

Further previous studies have shown that the most important treatment risk factor for lymphedema is ALND. ${ }^{12-14}$ Interestingly, in the present study, ALND was associated with a significantly increased risk of lymphedema, but did not affect overall survival.

To conclude, data from the present nonrandomized study and several other studies including randomized trials suggest that patients with breast cancer and clinically negative axillary nodes do not benefit from axillary dissection. Finally,

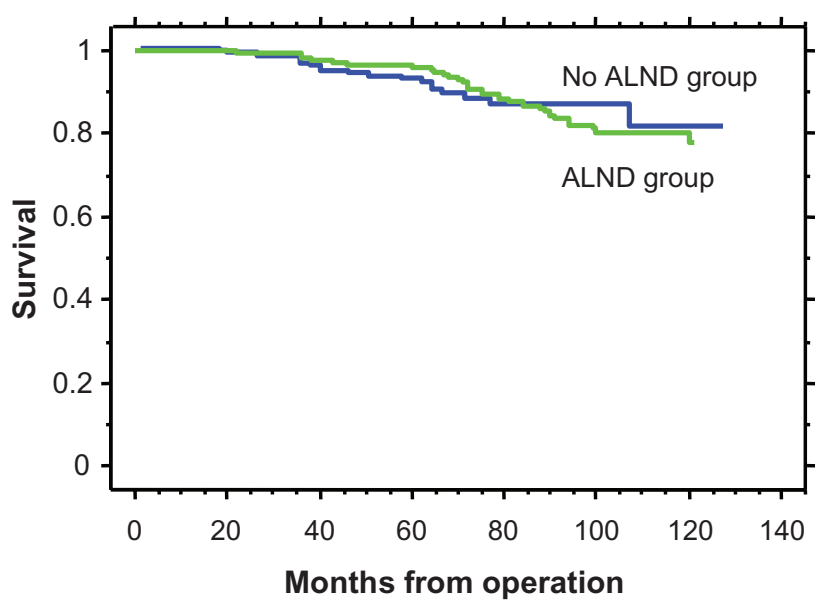

Figure 3 Overall survival curves are shown.

Note: The green line shows the ALND group and the blue line shows the no ALND group (log-rank $P>0.05$ ).

Abbreviation: ALND, axillary lymph node dissection.

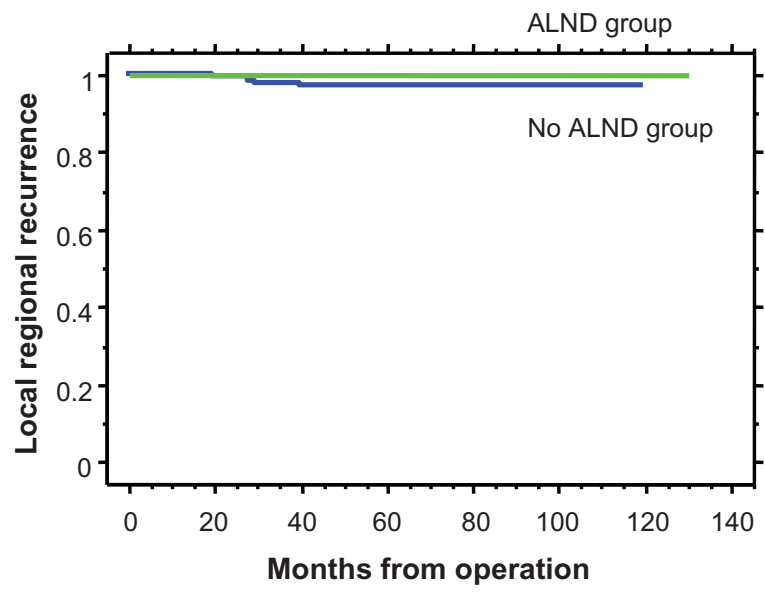

Figure 4 Local regional recurrence curves.

Note: The green line shows the ALND group and the blue line shows the no ALND group (log-rank $P>0.05$ ).

Abbreviation: ALND, axillary lymph node dissection.

we acknowledge that it would be preferable to confirm our findings with a randomized trial, notwithstanding the difficulties of conducting such trials in breast cancer.

\section{Disclosure}

The authors declare that they have no competing interests in this work.

\section{References}

1. Ozaslan C, Kuru B. Lymphedema after treatment of breast cancer. Am J Surg. 2004;187:69-72.

2. Schijven MP, Vingerhoets AJ, Rutten HJ, et al. Comparison of morbidity between axillary lymph node dissection and sentinel node biopsy. Eur J Surg Oncol. 2003;29:341-350.

3. Silberman AW, McVay C, Cohen JS, et al. Comparative morbidity of axillary lymph node dissection and the sentinel lymph node technique: implications for patients with breast cancer. Ann Surg. 2004; 240:1-6.

4. Mansel RE, Fallowfield L, Kissin M, et al. Randomized multicenter trial of sentinel node biopsy versus standard axillary treatment in operable breast cancer: the ALMANAC Trial. J Natl Cancer Inst. 2006;98: 599-609.

5. Fisher B, Redmond C, Fisher ER, et al. Ten-year results of a randomized clinical trial comparing radical mastectomy and total mastectomy with or without radiation. $N$ Engl J Med. 1985;312:674-681.

6. Fisher B, Jeong JH, Anderson S, Bryant J, Fisher ER, Wolmark N. Twenty-five-year follow-up of a randomized trial comparing radical mastectomy, total mastectomy, and total mastectomy followed by irradiation. N Engl J Med. 2002;347:567-575.

7. Krag DN, Anderson S, Julian TB, et al. Sentinel-lymph-node resection compared with conventional axillary-lymph-node dissection in clinically node-negative patients with breast cancer: overall survival findings from the NSABP B-32 randomized phase 3 trial. Lancet Oncol. 2010;11: 927-933.

8. Weaver DL, Ashikaga T, Krag DN, et al. Effect of occult metastases on survival in node-negative breast cancer. $N$ Engl J Med. 2011;364: 412-421.

9. de Boer M, van Deurzen CH, van Dijck JA, et al. Micrometastases or isolated tumor cells and the outcome of breast cancer. $N$ Engl J Med. 2009;361:653-663. 
10. Giuliano AE, McCall L, Beitsch P, et al. Locoregional recurrence after sentinel lymph node dissection with or without axillary dissection in patients with sentinel lymph node metastases: the American College of Surgeons Oncology Group Z0011 randomized trial. Ann Surg. 2010;252:426-433.

11. Leidenius M, Leivonen M, Vironen J, Smitten KV. The consequences of long-time arm morbidity in node-negative breast cancer patients with sentinel node biopsy or axillary clearance. J Surg Oncol. 2005;92:23-31.

12. Norman SA, Localio AR, Kallan MJ, et al. Risk factors for lymphedema after breast cancer treatment. Cancer Epidemiol Biomarkers Prev. 2010;19:2734-2746.
13. Soran A, D'Angelo G, Begovic M, et al. Breast cancer-related lymphedema - what are the significant predictors and how they affect the severity of lymphedema? Breast J. 2006;12:536-543.

14. Mak SS, Yeo W, Lee YM, et al. Predictors of lymphedema in patients with breast cancer undergoing axillary lymph node dissection in Hong Kong. Nurs Res. 2008;57:416-425.

\section{Publish your work in this journal}

Breast Cancer: Targets and Therapy is an international, peerreviewed open access journal focusing on breast cancer research, identification of therapeutic targets and the optimal use of preventative and integrated treatment interventions to achieve improved outcomes, enhanced survival and quality of life for the cancer patient.

\section{Dovepress}

View the full aims and scopes of this journal here. The manuscript management system is completely online and includes a very quick and fair peer-review system, which is all easy to use. Visit http:// www.dovepress.com/testimonials.php to read real quotes from published authors.

Submit your manuscript here: http://www.dovepress.com/breast-cancer---targets-and-therapy-journal 